\title{
A wind turbine sensorless automatic control systems, analysis, modelling and development of IDA-PBC method
}

\author{
Hamiani Hichem', Mansouri Abdellah'2 ${ }^{2}$ Tadjeddine Ali Abderrazak ${ }^{3}$, \\ Belaidi Abdelkader ${ }^{4}$, Salim Ramzi ${ }^{5}$ \\ 1,2,4.5 Department of Electrical Engineering, Laboratory of LAAS, Ecole Nationale Polytechnique d'Oran Maurice Audin, \\ Algeria \\ ${ }^{3}$ Department of Electrical Engineering, Laboratory of SCAMRE, Ecole Nationale Polytechnique d'Oran Maurice Audin,
} Algeria

\begin{tabular}{l} 
Article Info \\
\hline Article history: \\
Received May 7, 2019 \\
Revised Jul 8, 2019 \\
Accepted Jul 31, 2019 \\
\hline
\end{tabular}

\section{Keywords:}

DFIG, IDA-PBC control, MPPT, MRAS,

Sensorless control, Wind turbine control

\section{Corresponding Author:}

Hamiani Hichem, Department of Electrical Engineering, Laboratory of LAAS, National Polytechnic School of Oran, Maurice Audin, Oran, Algeria. Email: hichemhamiani@gmail.com
This is an open access article under the CC BY-SA license.

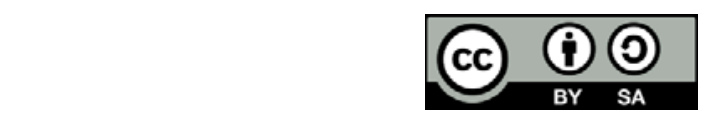

\begin{abstract}
Several non-linear controls are developed for controlling a wind energy conversion system equipped with a DFIG double feed asynchronous generator. Exploitation of the aerodynamic power captured by the turbine gives a new instruction to the controller based on passivity by keeping the hypersynchronous regime of the DFIG. An adaptive observer MRAS was developed for the considered as a structure in which the rotor speed is estimated from the measurement of stator and rotor currents. Our goal is to maximize active power, minimize construction costs in order to control wind turbine systems using our passivity and observation method. Best results were obtained using sensorless MPPT and IDA-PBC methods.
\end{abstract}

\section{INTRODUCTION}

The problem every day and around the world is to meet the energy demand that is growing more and more. The accelerated increase in industrial activity in countries and business investment that provides a lower cost of production has increased rapidly the global demand for energy. Faced with this demand, the industrialized countries have massively used the production of decentralized energies whether renewable or non-renewable sources $[1,2]$. Wind energy was the first of the energy sources exploited by man. This inexhaustible source of energy has developed significantly in recent decades $[2,3]$.

However, the large proportion of wind turbines uses DFIG (asynchronous double-feed generators). This generator allows variable speed electricity generation [4]. It gives the opportunity, to better control the wind resources for different wind conditions [5]. In the field of variable speed, the asynchronous generator and thanks to the development of electronic inverters, currently ensures, in addition, a very important market share. In the last years, an appreciable increase in the order of generators with double feeding have been given, where we can give the vector control, the direct control of the couple and the adaptive control.

Similarly, multi-scientific works on the DFIG have contributed to the controls of wind systems (backstepping control, Sliding mode control, MPPT control, PCHD Model control, D-FOC control etc. [1, 2, 6-10]. 
The major disadvantage of these commands is assembled on a rigorous mathematical aspect for synthesized. In contrast, there are other commands that have a physical meaning such as passive control [11-14].

Passivity-based control is a well-established technique that has been very powerful in designing robust controls for physical systems. Inherited from well-known physical phenomena, notions of passivity are adapted to several scientific domains and are effective for the regulation of electrical, mechanical and electromechanical systems present in several fields of engineering, such as robotics, power electronics etc. $[6,15,16]$.

Passivity-based control provides robust controllers that have a clear physical interpretation in terms of the system's interconnections with its environment. In particular, the total energy of the closed-loop system is the difference between the energy of the system and the energy supplied by the controller [7]. Moreover, since the Euler-Lagrange structure is preserved in a closed loop, the passivity control has a robust stability with respect to the non-modelled dissipative effects and exhibits robust performances due to its inverse optimality [8, 9]. Modeling in PCH (Port Controlled Hamiltonian) form and its use for non-linear system control has already been successfully applied in many areas of physics to describe these systems in terms of exchange of energy [17]. This by generalizing the notion of Dirac structure into an interconnection structure that makes it possible to clearly write the interaction of the system with its environment $[18,19]$.

The structure that includes power converters on the rotor part provides a high degree of controllability, and allows for maximum efficiency at all wind speeds. To ensure the control of MPPT (Maximum Power Point Tracking) we used the diagram presented in Figure 1 [20, 21].

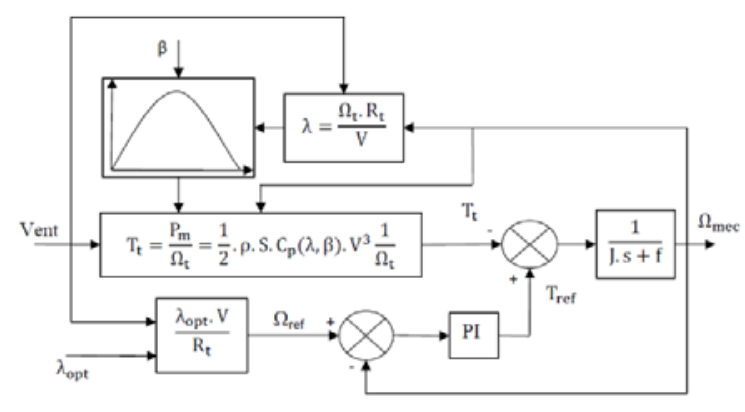

Figure 1. Block diagram with speed control

The control scheme of the DFIG requires that the rotor speed in optimal operation, therefore, the use of speed sensor to ensure this magnitude implies the increase in installation complexity and cost. For this purpose, the Model Reference Adaptive System (MRAS) observer was used to estimate the rotor position from two rotor flux models (reference model, adjustable model) to obtain the rotor speed [21]. Figure 2 presents the schematic diagram of an MRAS observer.

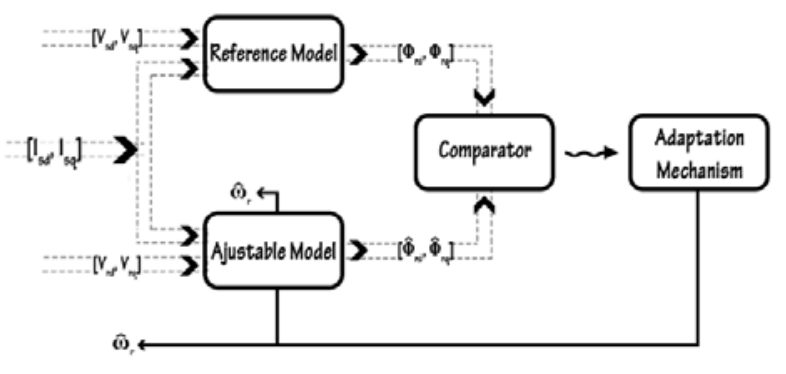

Figure 2. Principle diagram of an MRAS observer

Nevertheless, the objective of this work shows the resolution of the three problems generally encountered in the control of the DFIG, then the first problem is the complexity of the mathematical equations which classically models the system to study, the second problem is the minimization of the costs of construction by the elimination of mechanical sensors, and finally we model and control the production chain in closed loop. Therefore, the

Int J Pow Elec \& Dri Syst Vol. 11, No. 1, Mar 2020 : $45-55$ 
proposed solutions present equations that have a physical aspect (energetic) and a non linear control IDA-PBC (Interconnection and Damping Assignment - Passivity Based Control) without a mechanical speed sensor associated with a wind turbine integrated into the electrical network (Figure 3 shows the overall system studied). The structure of this contribution is based on the modeling and control of the system, results and discussion finally a conclusion and perspective. Variants and scenarios are performed under the Matlab / Simulink environment to evaluate the reliability and robustness of sensorless passive control.

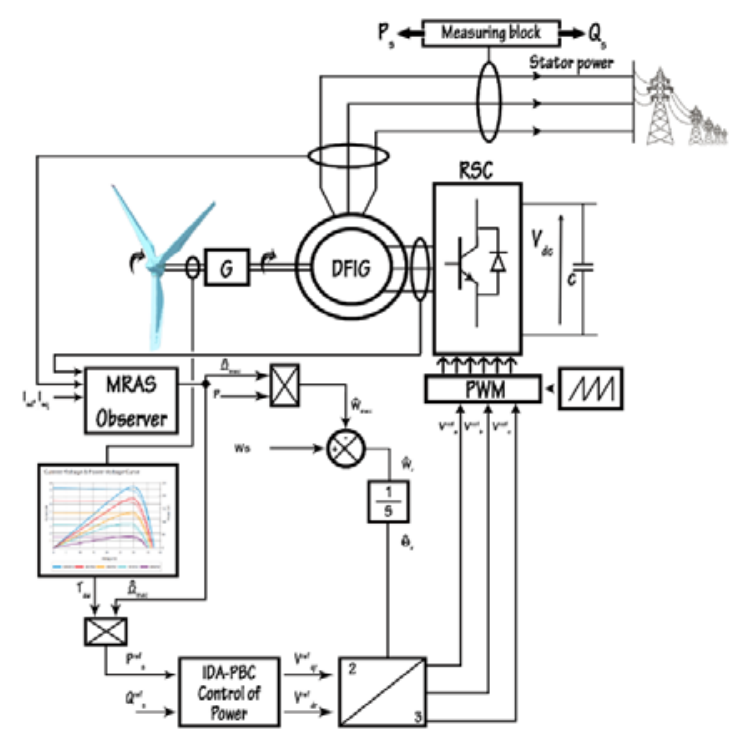

Figure 3. Structure of sensorless control with IDA-PBC method for the DFIG

\section{MODELING OF THE WIND SYSTEM}

\subsection{Modeling of the wind turbine}

The wind power equation is defined from the following way [3]:

$$
P_{v}=\frac{1}{2} \rho \cdot S \cdot v^{3}
$$

$\rho:$ is the density of the air.

$S:$ is the circular surface swept by the turbine.

$v:$ is the wind speed $(\mathrm{m} / \mathrm{s})$.

The aerodynamic power of the turbine is then written:

$$
P_{\text {aero }}=C_{p} \cdot P_{v}=C_{p}(\lambda, \beta) \frac{1}{2} \rho \cdot S \cdot v^{3}
$$

With $\lambda$ which represents the specific speed $\lambda=\frac{R \Omega_{\text {wind }}}{v}$

The power coefficient $\mathrm{Cp}$ represent the aerodynamic yield of the wind turbine, it is determined as following:

$$
C_{p}(\lambda, \beta)=C_{1}\left(C_{2} \frac{1}{\Lambda}-C_{3} \beta^{x}-C_{4}-C_{5}\right) e^{\frac{-C_{6}}{\Lambda}}
$$

Knowing that:

$$
\frac{1}{\Lambda}=\left(\frac{1}{\lambda+0.08 \beta}-\frac{0.035}{1+\beta^{3}}\right)
$$

The torque of the wind turbine is given by: 


$$
T_{m e c}=\frac{P_{m e c}}{w}=\frac{1}{2} \frac{\rho . S \cdot v^{3} C_{p}(\lambda, \beta)}{w}
$$

The fundamental equation of dynamics allows determine the evolution of the mechanical speed from the total mechanical torque Tmec applied to the rotor:

$$
J \frac{d \Omega_{m e c}}{d t}=T_{m e c}
$$

$J:$ is the total inertia that appears on the rotor of the generator.

$$
J=\frac{J_{\text {turbine }}}{G}+J_{D F I G}
$$

This mechanical torque Tmec takes into account, the electromagnetic torque Tem produced by the generator, the Torque of viscous friction Tvis, and the torque from the gearbox $T_{g}$.

$$
T_{m e c}=T_{g}-T_{e m}-T_{v i s}
$$

\subsection{Modeling of the DFIG}

The model of the double-feed generator in the d-q reference can be written as below [8]:

$$
\left\{\begin{array}{l}
V_{d s}=R_{s} I_{d s}+\frac{d \Phi_{d s}}{d t}-\omega_{s} \Phi_{q s} \\
V_{q s}=R_{s} I_{q s}+\frac{d \Phi_{q s}}{d t}-\omega_{s} \Phi_{d s} \\
V_{d r}=R_{r} I_{d r}+\frac{d \Phi_{d r}}{d t}-\omega_{r} \Phi_{q r} \\
V_{q r}=R_{r} I_{q r}+\frac{d \Phi_{q r}}{d t}-\omega_{r} \Phi_{d r}
\end{array}\right.
$$

With :

$$
\begin{gathered}
\omega_{r}=\omega_{s}-P \Omega \\
\left\{\begin{array}{l}
\Phi_{d s}=L_{s} I_{d s}+M I_{d r} \\
\Phi_{q s}=L_{s} I_{q s}+M I_{q r} \\
\Phi_{d r}=L_{r} I_{d r}+M I_{d s} \\
\Phi_{q r}=L_{r} I_{q r}+M I_{q s}
\end{array}\right.
\end{gathered}
$$

The expression of the electromagnetic torque of the DFIG depending on flow and stator currents can be written as follows:

$$
T_{e m}=-P \frac{M}{L_{s}}\left(\Phi_{q s} I_{d r}-\Phi_{d s} I_{q r}\right)
$$

With $\mathrm{p}$ : number of pole pairs of the DFIG.

The active and reactive powers stator and rotor of the DFIG are written as follows [15]:

$$
\left\{\begin{array}{l}
P_{s}=V_{d s} I_{d s}+V_{q s} I_{q s} \\
Q_{s}=V_{q s} I_{d s}-V_{d s} I_{q s} \\
P_{r}=V_{d r} I_{d r}+V_{q r} I_{q r} \\
Q_{r}=V_{q r} I_{d r}-V_{d r} I_{q r}
\end{array}\right.
$$

\subsection{IDA-PBC controller applied to DFIG generator}

From (09), it is clear that the dynamic model of the DFIG is non-linear due to the coupling between the speed and the electric currents. According to the vector control principle, the direct axis current Id is always forced to equal zero in order to orient all the linkage flux in the $\mathrm{d}$ axis and achieve maximum torque per ampere.

Int J Pow Elec \& Dri Syst Vol. 11, No. 1, Mar 2020 : $45-55$ 


$$
\left\{\begin{array}{l}
\frac{d \Phi_{d s}}{d t}=V_{d s}-R_{s} I_{d s}+\omega_{s} L_{s} I_{q s}+\omega_{s} M I_{q r} \\
\frac{d \Phi_{q s}}{d t}=V_{q s}-R_{s} I_{q s}-\omega_{s} L_{s} I_{d s}-\omega_{s} M I_{d r} \\
\frac{d \Phi_{d r}}{d t}=V_{d r}-R_{r} I_{d r}+\omega_{r} L_{r} I_{q r}+\omega_{r} M I_{q s} \\
\frac{d \Phi_{q r}}{d t}=V_{q r}-R_{r} I_{q r}-\omega_{r} L_{r} I_{d r}+\omega_{r} M I_{d s}
\end{array}\right.
$$

So the mechanical equation of the rotating part of the generator is given by:

$$
\begin{aligned}
& J \frac{d \omega}{d t}=M I_{s}^{T} J_{2} I_{r}-T_{r}-T_{f} \\
& \text { Where } ; J_{2}=\left[\begin{array}{cc}
0 & -1 \\
1 & 0
\end{array}\right], I_{s}=\left[\begin{array}{l}
I_{d s} \\
I_{q s}
\end{array}\right], I_{r}=\left[\begin{array}{l}
I_{d r} \\
I_{q r}
\end{array}\right]
\end{aligned}
$$

The state variables are :

$$
x=\left[\begin{array}{lll}
\Phi_{s}^{T} & \Phi_{r}^{T} & J \omega
\end{array}\right]^{T}=\left[\begin{array}{ll}
x_{e}^{T} & x_{m}
\end{array}\right]^{T}
$$

With :

$x_{e}^{T}=\left[\begin{array}{ll}\Phi_{s}^{T} & \Phi_{r}^{T}\end{array}\right]:$ are the electric state variables.

$x_{m}=J \omega:$ mechanical variable.

The energy function written by:

$$
H(x)=\frac{1}{2} x_{e}^{T} L^{-1} x_{e}+\frac{1}{2 J_{D F I G}} x_{m}^{2}
$$

With :

$$
L=\left[\begin{array}{ll}
L_{s} I_{2} & M I_{2} \\
M I_{2} & L_{r} I_{2}
\end{array}\right], I_{2}=\left[\begin{array}{ll}
1 & 0 \\
0 & 1
\end{array}\right]
$$

The partial derivatives of energy with respect to the state variables are:

$$
\left\{\begin{array} { c } 
{ \frac { \partial H } { \partial x _ { e } } = L ^ { - 1 } x _ { e } } \\
{ \frac { \partial H } { \partial x _ { m } } = J ^ { - 1 } x _ { m } }
\end{array} \Rightarrow \left\{\begin{array}{c}
\frac{\partial H}{\partial x_{e}}=I=\left[\begin{array}{ll}
I_{s}^{T} & I_{r}^{T}
\end{array}\right]^{T} \\
\frac{\partial H}{\partial x_{m}}=\omega
\end{array}\right.\right.
$$

Finally, the matrices of interconnection, damping and the matrix of the command are :

$$
\begin{aligned}
& J(x)=\left[\begin{array}{ccc}
-\omega_{s} L_{s} J_{2} & -\omega_{s} M J_{2} & 0_{2 \times 1} \\
-\omega_{s} L_{s} J_{2} & -\omega_{r} L_{s} J_{2} & M J_{2} I_{s} \\
0_{1 \times 2} & M I_{s}^{T} J_{2} & 0
\end{array}\right], R(x)=\left[\begin{array}{ccc}
R_{s} I_{2} & 0_{2 \times 2} & 0_{2 \times 1} \\
0_{2 \times 2} & R_{r} I_{2} & 0_{2 \times 1} \\
0_{1 \times 2} & 0_{1 \times 2} & T_{f}
\end{array}\right] \\
& \mathrm{g}(x)=\left[\begin{array}{ccc}
I_{2} & 0_{2 \times 2} & 0_{2 \times 1} \\
0_{2 \times 2} & I_{2} & 0_{2 \times 1} \\
0_{1 \times 2} & 0_{1 \times 2} & 1
\end{array}\right], u=\left[\begin{array}{lll}
V_{s}^{T} & V_{r}^{T} & T_{r}
\end{array}\right]^{T}
\end{aligned}
$$

With :

$$
\begin{aligned}
& 0_{2 \times 2}=\left[\begin{array}{ll}
0 & 0 \\
0 & 0
\end{array}\right], 0_{2 \times 1}=\left[\begin{array}{l}
0 \\
0
\end{array}\right], 0_{1 \times 2}=\left[\begin{array}{ll}
0 & 0
\end{array}\right], V_{s}^{T}=\left[\begin{array}{l}
V_{d s} \\
V_{q s}
\end{array}\right], V_{r}^{T}=\left[\begin{array}{l}
V_{d r} \\
V_{q r}
\end{array}\right] \\
& J(x)=J(x)^{-1}, R(x)=R(x)^{T} \geq 0
\end{aligned}
$$

With these matrices the model PCH is written by: 


$$
\begin{aligned}
\dot{x} & \left.=\left[\begin{array}{ccc}
-\omega_{s} L_{s} J_{2} & -\omega_{s} M J_{2} & 0_{2 \times 1} \\
-\omega_{s} M J_{2} & -\omega_{r} L_{s} J_{2} & M J_{2} I_{S} \\
0_{1 \times 2} & M I_{s}^{T} J_{2} & 0
\end{array}\right]-\left[\begin{array}{ccc}
R_{S} I_{2} & 0_{2 \times 2} & 0_{2 \times 1} \\
0_{2 \times 2} & R_{r} I_{2} & 0_{2 \times 1} \\
0_{1 \times 2} & 0_{1 \times 2} & T_{f}
\end{array}\right]\right] \nabla H+\left[\begin{array}{ccc}
I_{2} & 0_{2 \times 2} & 0_{2 \times 1} \\
0_{2 \times 2} & I_{2} & 0_{2 \times 1} \\
0_{1 \times 2} & 0_{1 \times 2} & 1
\end{array}\right]\left[\begin{array}{c}
V_{s}^{T} \\
V_{r}^{T} \\
T_{r}
\end{array}\right] \\
\dot{y} & =\left[\begin{array}{ccc}
I_{2} & 0_{2 \times 2} & 0_{2 \times 1} \\
0_{2 \times 2} & I_{2} & 0_{2 \times 1} \\
0_{1 \times 2} & 0_{1 \times 2} & 1
\end{array}\right] \nabla H
\end{aligned}
$$

\subsection{Calculation of control voltages Vdr, Vqr :}

To calculate the control voltages one has to determine $J_{d}(x)$ and $R_{d}(x)$

For that we must determine $J_{a}(x), R_{a}(x)$ the controller. The closed-loop system is written by:

Where :

$$
f(x)+\mathrm{g}(x) u=\left(J_{d}(x)-R_{d}(x)\right) \partial H_{d}(x)
$$

$$
\begin{aligned}
& J_{d}(x)=J(x)+J_{a}(x) \\
& R_{d}(x)=R(x)+R_{a}(x) \\
& H_{d}(x)=H(x)+H_{a}(x)
\end{aligned}
$$

With :

$H_{d}(x)$ : The energy function of the closed-loop system, $H_{a}(x)$ : The controller energy function.

$J_{d}(x)$ : The interconnection matrix of the closed-loop system, $J_{a}(x)$ : The controller interconnection matrix. $R_{d}(x)$ : The damping matrix of the closed-loop system, $R_{a}(x)$ : The controller damping matrix It is possible to write (26) as follows:

$$
\left(J(x)+J_{a}(x)-R(x)+R_{a}(x)\right) \partial H_{d}(x)=-\left(J_{a}(x)-R_{a}(x)\right) \partial H(x)+\mathrm{g}(x) u
$$

The previous equation is equivalent to:

$$
\left(J_{d}(x)-R_{d}(x)\right) \partial H_{a}(x)=-\left(J_{a}(x)-R_{a}(x)\right) \partial H(x)+\mathrm{g}(x) u
$$

So the total energy desired:

$$
H_{d}(x)=\frac{1}{2}\left(x_{e}-x_{e}^{*}\right)^{T} L^{-1}\left(x_{e}-x_{e}^{*}\right)+\frac{1}{2 J_{D F I G}}\left(x_{m}-x_{m}^{*}\right)^{2}
$$

So :

$$
H_{a}(x)=H_{d}(x)-H(x)=-x_{e}^{T} L^{-1} x_{e}-\frac{1}{J_{D F I G}} x_{m}^{*} x_{m}+\frac{1}{2} x_{e}^{* T} L^{-1} x_{e}^{*}+\frac{1}{2 J_{D F I G}} x_{e}^{* 2}
$$

With :

$$
\partial H_{a}(x)=\left[\begin{array}{l}
-I^{*} \\
-\omega^{*}
\end{array}\right], \text { where } I=\left[\begin{array}{llll}
I_{d s} & I_{q s} & I_{d r} & I_{q r}
\end{array}\right]^{T}
$$

Using this relationship, (28) becomes :

$$
\left(J_{d}(x)-R_{d}(x)\right)\left[\begin{array}{c}
-I^{*} \\
-\omega^{*}
\end{array}\right]=-\left(J_{a}(x)-R_{a}(x)\right)\left[\begin{array}{c}
I \\
\omega
\end{array}\right]+g(x) u
$$

The command $\mathrm{Vr}$ is found in line 3 and 4 of the matrix in (31).

So : 


$$
J_{a}(x)=\left[\begin{array}{ccc}
0_{2 \times 2} & 0_{2 \times 2} & 0_{2 \times 1} \\
0_{2 \times 2} & 0_{2 \times 2} & -J_{r m}(x) \\
0_{1 \times 2} & J_{r m}^{T}(x) & 0
\end{array}\right], R_{a}(x)=\left[\begin{array}{ccc}
0_{2 \times 2} & 0_{2 \times 2} & 0_{2 \times 1} \\
0_{2 \times 2} & r I_{2} & 0_{2 \times 1} \\
0_{1 \times 2} & 0_{1 \times 2} & 0
\end{array}\right]
$$

Where :

$$
J_{r m}(x) \in \Re^{2 \times 1} \text { to be determined. }
$$

$\mathrm{r}:$ It is an additional resistance for currents to dampen transient oscillations.

We replace the matrices $J_{a}(x), R_{a}(x)$ and using (30), we find:

$$
J_{r m}^{T}(x)=M \frac{\left(I_{r}-I_{r}^{*}\right)^{T}}{\left|I_{r}-I_{r}^{*}\right|^{2}}\left(I_{s}-I_{s}^{*}\right)^{T} J_{2} I_{r}^{*}
$$

So :

$$
V_{r}=V_{r}^{*}-\left(\omega-\omega^{*}\right)\left(L_{r} J_{2} I_{r}^{*}+J_{r m}(x)\right)-M \omega^{*} J_{2}\left(I_{s}-I_{s}^{*}\right)-r I_{2}\left(I_{r}-I_{r}^{*}\right)
$$

Unfortunately, the order is singular in point of equilibrium. It's done possible to get rid of this singularity by adding a depreciation variable. Now we keep $J_{d}(x)$ and $H_{d}(x)$ as before, and we change the matrix to have the form:

$$
R_{a}(x)=\left[\begin{array}{ccc}
0_{2 \times 2} & 0_{2 \times 2} & 0_{2 \times 1} \\
0_{2 \times 2} & r I_{2} & 0_{2 \times 1} \\
0_{1 \times 2} & 0_{1 \times 2} & \xi(x)
\end{array}\right]
$$

With :

$$
\xi(x)=\frac{T_{e m}^{*}-T_{e m}\left(x_{e}\right)}{\omega-\omega^{*}}
$$

and :

$$
T_{e m}^{*}=C_{f} \omega^{*}
$$

When replaced in the closed-loop Hamiltonian equation, $\xi(x)$ is multiplied by $\left(\omega-\omega^{*}\right)$, therefore elimination of singularity. Since the mechanical part of (27) is the only one that has been modified, then the expression of $\mathrm{Vr}$ in terms of $J_{r m}(x)$ rest the same.

Using the equilibrium equations, we obtain:

$$
J_{r m}(x)=M J_{2} I_{s}
$$

The closed-loop dynamic system is always of the form (24) with:

$$
J_{d}(x)=\left[\begin{array}{ccc}
-\omega_{s} L_{s} J_{2} & -\omega_{s} M J_{2} & 0_{2 \times 1} \\
-\omega_{s} M J_{2} & -\omega_{r} L_{s} J_{2} & M J_{2} I_{s} \\
0_{1 \times 2} & M I_{s}^{T} J_{2} & 0
\end{array}\right] ; R_{d}(x)=\left[\begin{array}{ccc}
R_{s} I_{2} & 0_{2 \times 2} & 0_{2 \times 1} \\
0_{2 \times 2} & \left(R_{r}+r\right) I_{2} & 0_{2 \times 1} \\
0_{1 \times 2} & 0_{1 \times 2} & T_{f}+\xi(x)
\end{array}\right]
$$

Finally, the rotor voltages of the order are written by:

$$
V_{r}=V_{r}^{*}-\left(\omega-\omega^{*}\right)\left(L_{r} J_{2} I_{r}^{*}+M J_{2} I_{s}\right)-M \omega^{*} J_{2}\left(I_{s}-I_{s}^{*}\right)-r I_{2}\left(I_{r}-I_{r}^{*}\right)
$$

With:

$$
V_{r}^{*}=\left(\omega_{s}-\omega^{*}\right)\left(L_{r} J_{2} I_{r}^{*}+M J_{2} I_{s}\right)+R_{r} I_{2} I_{r}^{*}
$$

\subsection{Application of the MRAS}

The equations of the chosen reference model and adaptive model are given by:

A wind turbine sensorless automatic control systems, analysis, modelling and ... (Hamiani Hichem) 
Reference model:

$$
\begin{aligned}
& \frac{d \Phi_{d r}}{d t}=\frac{L_{r}}{M}\left(V_{d s}-R_{s} I_{d s}-\sigma L_{s} \frac{d I_{d s}}{d t}\right) \\
& \frac{d \Phi_{q r}}{d t}=\frac{L_{r}}{M}\left(V_{q s}-R_{s} I_{q s}-\sigma L_{s} \frac{d I_{q s}}{d t}\right)
\end{aligned}
$$

Adaptive model:

$$
\begin{aligned}
& \frac{d \Phi_{d r}}{d t}=V_{d s}-\frac{1}{T_{r}} \widehat{\Phi}_{d r}-\widehat{\omega} \widehat{\Phi}_{q r}+\frac{M}{T_{r}} I_{d s} \\
& \frac{d \widehat{\Phi}_{q r}}{d t}=V_{q s}-\frac{1}{T_{r}} \widehat{\Phi}_{q r}-\widehat{\omega} \widehat{\Phi}_{d r}+\frac{M}{T_{r}} I_{q s}
\end{aligned}
$$

The error between the two models, function to be minimized, is given by:

$$
\varepsilon=\Phi_{r}-\widehat{\Phi}_{r}
$$

The law of adaptation presents an integration in open loop (problem of offset). For the improvement of the estimation response a low pass filter has been proposed by many authors [10]:

$$
\omega=K_{p}\left(\varepsilon_{d} \widehat{\Phi}_{q r}-\varepsilon_{q} \widehat{\Phi}_{d r}\right)+K_{i}\left(\varepsilon_{d} \widehat{\Phi}_{q r}-\varepsilon_{q} \widehat{\Phi}_{d r}\right) d t
$$

With: $K_{p}, K_{i}$ positive constants.

\section{RESULTS AND DISCUSSION}

Using Matlab/Simulink, the results obtained for the sensorless IDA-PBC command are presented in Figure 4, Figure 5, Figure 6, and Figure 7 shows the reference of the dynamic wind speed.
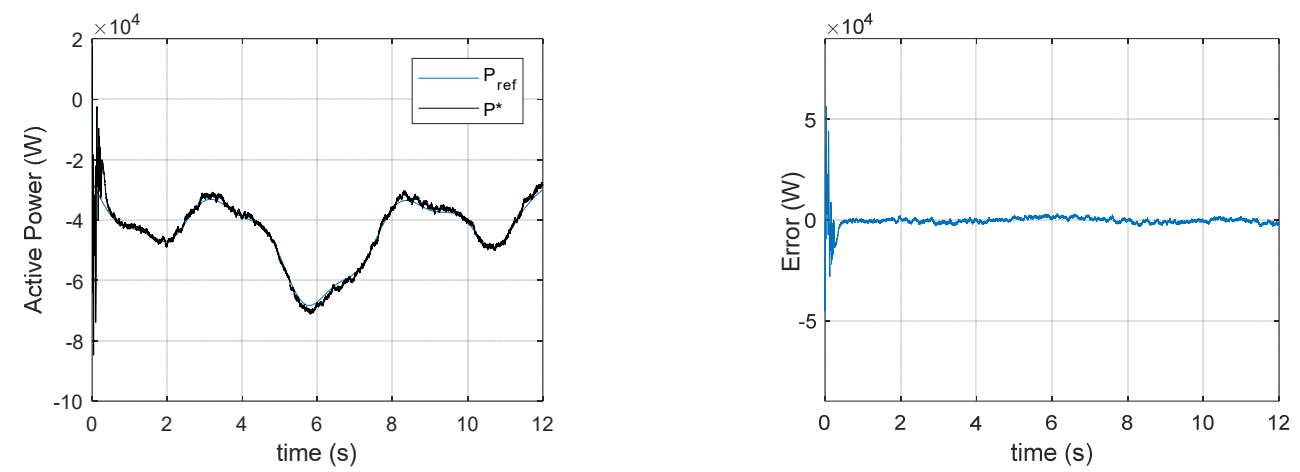

Figure 4. Results of the active power with its error, without sensor.
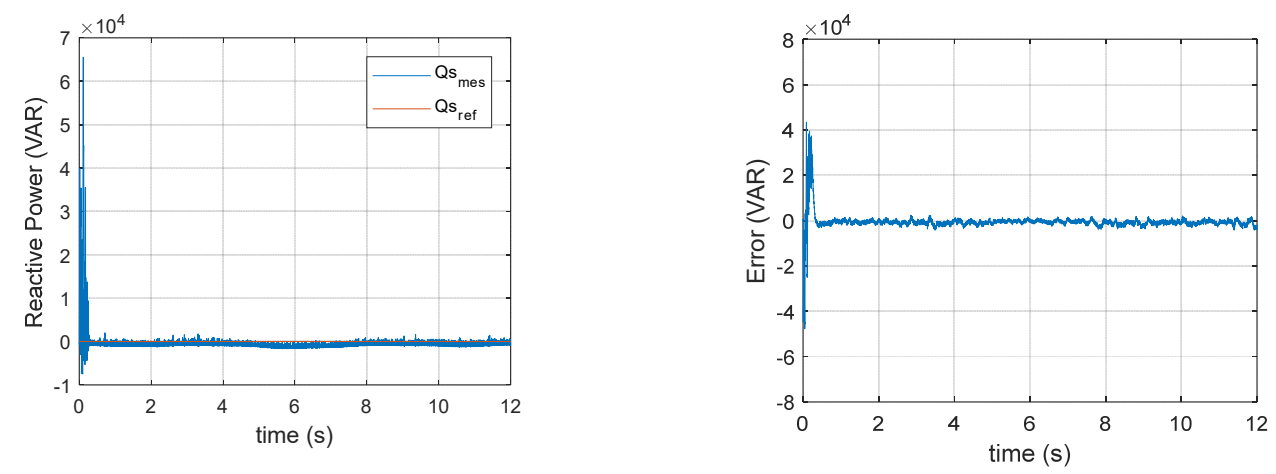

Figure 5. Results of the reactive power with its error, without sensor. 

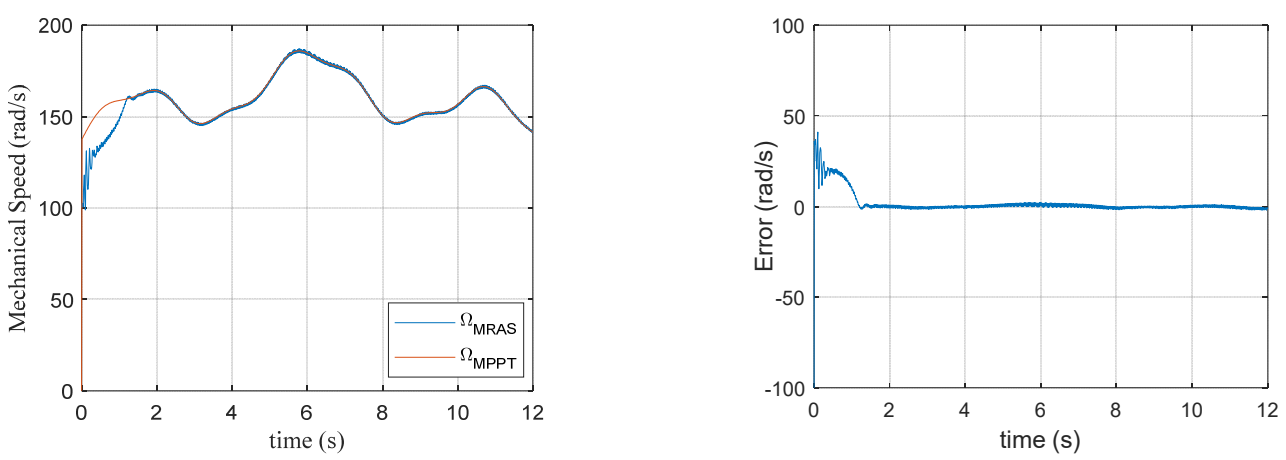

Figure 6. Results of the mechanical speed with its error, without sensor.

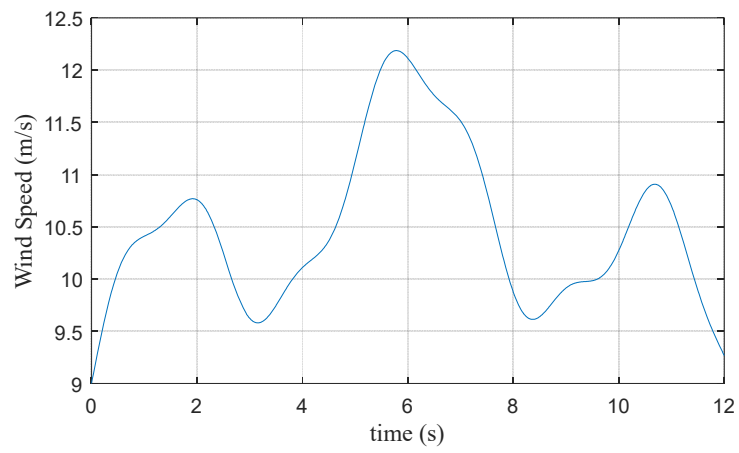

Figure 7. The reference of the dynamic wind speed.

\section{DISCUSSION}

Using an MRAS observer with a dynamic (random) wind speed, the results obtained for Figure 5 show the evolution of the active power provided by the DFIG with its error as a function of time. Note that the curve of the active power $\mathrm{P}^{*}$ (in black) followed by the other of the reference (in blue) Pref with a transient regime of 0.25 seconds. The maximum peak at $72 \mathrm{KW}$ for a wind speed of $12.2 \mathrm{~m} / \mathrm{s}$. It is seen that the curve of the active power $\mathrm{P}^{*}$ and its error have small fluctuations because of the properties of the observer MRAS due to the sensitivity to the dynamic variations of the turbine.

Under the same conditions described above, Figure 6 shows the evolution of the reactive power supplied to the minimum values by the DFIG with its error as a function of time. It is noted that the curve of the reactive power Qsmes (in blue) followed the other of the reference (in red) Qsref with a transient regime of 0.25 seconds. The maximum value generated from the reactive power is 1.3 Kvar for a wind speed of 12.2 $\mathrm{m} / \mathrm{s}$. This minimum value of the reactive power produced is the consequence of the coupling of the mathematical model of the DFIG use. The small fluctuations on the Qsmes curve is the cause of the properties of the MRAS observer.

In the same conditions described previously, Figure 7 presents the dynamic variation of the mechanical speed with its error as a function of time. Note that the observed speed curve $\Omega$ MRAS (in blue) followed the measured speed $\Omega$ MPPT curve (in red) with a transient period of 0.25 seconds. In this case, the transient regime is divided into two parts, the first part where the starting time of the system from 0 to 0.25 seconds as well as the second part is the delayed time of the observed speed SMRAS with respect to the speed measured $\Omega$ MPPT between 0.25 and 1.5 seconds. This delay is the cause of adaptation mechanism (PI regulator) of the observer in which it was favored the accuracy of observation with respect to speed. The maximum value of the observed speed is $186 \mathrm{rad} / \mathrm{s}$ for a wind speed of $12.2 \mathrm{~m} / \mathrm{s}$. The small fluctuations on the speed curve $\Omega$ MRAS is the cause of the properties of our observer.

It can be seen that the reference curves for the active power, which reactivates the mechanical speed, has been perfectly followed thanks to the IDA-PBC command and the MPPT command for the dynamic variations of the wind. The error curves of the active and reactive powers take important values at startup for the transient regime and remain in the average of zero for the permanent regime.

A wind turbine sensorless automatic control systems, analysis, modelling and ... (Hamiani Hichem) 


\section{CONCLUSION}

In this contribution, the MRAS observer and an IDA-PBC controller are developed using advanced tools of nonlinear control for wind systems to a DFIG dual feed asynchronous generator. By using both MPPT and IDA-PBC commands that guarantee the maximization of the tracked power and the robustness of tracking the dynamic variations of the wind. Minimization of tracking errors for active and reactive powers are important to ensure reliability of power generation under normal conditions. The results obtained for the generated active power and the mechanical speed of the turbine in the dynamic conditions guarantee the robustness of our control and the validity of the model proposed, therefore, the precision and the optimization to track the variations of the aerodynamic powers.

\section{APPENDIX}

The parameters used in the model of the DFIG and wind turbine are shown in Table 1:

Table 1. Parameters used in simulation model.

\begin{tabular}{|c|c|c|}
\hline \multicolumn{3}{|c|}{ DFIG } \\
\hline Parameter & Value & Unit \\
\hline Pn & 100 & $\mathrm{~kW}$ \\
\hline Rs & 0.455 & $\Omega$ \\
\hline $\mathrm{Rr}$ & 0.19 & $\Omega$ \\
\hline Ls & 0.07 & $\mathrm{H}$ \\
\hline $\mathrm{Lr}$ & 0.0213 & $\mathrm{H}$ \\
\hline $\mathrm{Lm}$ & 0.034 & $\mathrm{H}$ \\
\hline JDFIG & 0,53 & $\mathrm{Kg} \cdot \mathrm{m}^{2}$ \\
\hline $\mathrm{f}$ & 0,0024 & N.m.s/rad \\
\hline $\mathrm{p}$ & 2 & 1 \\
\hline \multicolumn{3}{|c|}{ Wind Turbine } \\
\hline $\mathrm{R}$ & 35.25 & $\mathrm{~m}$ \\
\hline $\mathrm{S}$ & $\pi . r 2$ & $\mathrm{~m} 2$ \\
\hline$\rho$ & 1.22 & $\mathrm{Kg} / \mathrm{m} 3$ \\
\hline G & 90 & 1 \\
\hline Jturbine & 1000 & $\mathrm{Kg} / \mathrm{m} 2$ \\
\hline
\end{tabular}

\section{REFERENCES}

[1] B. Bossoufi, M. Karim, et al., "Observer backstepping control of DFIG-generators for wind turbines variablespeed: FPGA based implementation," Renewable Energy Journal (ELSIVER), vol. 81, pp. 903-917, September 2015.

[2] H. Wai (Alan) Lio, "Blade-pitch control for wind turbine load reductions," Book, Fst Edition springer, 2018.

[3] R. Hamid K., "Structural control and fault detection of wind turbine systems," Book, Fst Edition IET, 2018.

[4] R. Cardenas, R. Pena, et al., "Overview of control systems for the operation of DFIGs in wind energy applications," IEEE Transactions on Industrial Electronics, vol. 60, No. 7, pp. 2776-2798, 2013.

[5] A. Ghani A., A. Tahour, "Wind turbines design, control and applications," Book, Fst Edition ExLi4EvA, 2016.

[6] I. Minka, A. Essadki, S. Mensou, T. Nasser, "Primary frequency control applied to the wind turbine based on the DFIG controlled by the ADRC," International Journal of Power Electronics and Drive System (IJPEDS), vol. 10, No. 2, pp. 1049-1058, 2019.

[7] M. Nadour, A. Essadki, T. Nasser, M. Fdaili, "Robust coordinated control using backstepping of flywheel energy storage system and DFIG for power smoothing in wind power plants," International Journal of Power Electronics and Drive System (IJPEDS), vol. 10, No. 2, pp. 1110-1122, 2019.

[8] J. Wang, H. Yin, "Passivity based controller design based on EL and PCHD model," Elsevier Ltd, Procedia Engineering, vol. 15, pp. 33-37, 2011.

[9] A. Mahrous, K. Metwaly, I. Nagy, "Performance investigation of multi-level inverter for DFIG during grid autoreclosure operation," International Journal of Power Electronics and Drive System (IJPEDS), Vol. 10, no. 1, pp. 454-462, 2019.

[10] M. Zair, A. Hazzab, "MRAS speed sensorless vector control of induction motor drives using predictive adaptation mechanism," International Journal of Power Electronics and Drive System (IJPEDS), vol. 9, no. 4, pp. 1523-1533, 2018.

[11] H. Mahmoudi, "Backstepping adaptive control of DFIG for wind turbines variable-speed," JATIT Journal, 20th. vol. 81, no. 2, 2015.

[12] N. Luo, Y. Vidal and L. Acho, "Advances in industrial control, wind turbine control and monitoring," Book, Fst Edition springer, 2014.

[13] S. Ebrahimkhani, "Robust fractional order sliding mode control of doubly-fed induction generator -based wind turbines," ISA Transactions, 2016.

Int J Pow Elec \& Dri Syst Vol. 11, No. 1, Mar 2020 : 45 - 55 
[14] L. Jerbi, L. Krichen and A. Ouali, "Sensorless maximum power point tracking control for wind energy conversion system using DFIG," Journal of Electrical Engineering, pp. 1-8, 2009.

[15] T. Ashish, "Automatic control of atmospheric and space flight vehicles," Book, Fst Edition Birkhauser, 2011.

[16] X. Zheng, R. Song, H. Li, "Full-order terminal sliding mode stator flux observer for DFIG," IEEE, 11th Conference on Industrial Electronics and Applications (ICIEA), 978-1-4673-8644-9 vol. 16, 2016.

[17] S. Mensou, A. Essadki, et al., "Performance of a vector control for DFIG driven by wind turbine: real time simulation using DS1104 controller board," International Journal of Power Electronics and Drive System (IJPEDS), vol. 10(2), pp. 1003-1013, 2019.

[18] B. Bossoufi, H. Aroussi, et al., "Low-speed sensorless control of DFIG generators drive for wind turbines system," WSEAS transactions on systems and control, vol. 9, no. 4, pp. 514-525, 2014.

[19] R. Ortega, A. Schaft, et al., "Interconnection and damping assignment passivity-based control of port-controlled Hamiltonian systems [J]," Automatica, vol. 38, no. 4, pp. 585-596, 2002.

[20] R. Ortega, E. Garc, "Interconnection and damping assignment passivity-based control; a survey," European Journal of Control, 10, no. 5, pp. 432-450, 2004.

[21] D. Van, A. Schaft, "Gain and passivity techniques in nonlinear control," Second edition Berlin, Springer-Verlag, 2000. 